\title{
REVIEWS OF BOOKS
}

Venereal Disease in Britain. By Sydney M. Laird, M.D., F.R.F.P.S., D.P.H., Maj. R.A.M.C.

80 pp. Penguin Books, Ltd. Harmondsworth, 1943. Price 9d.

At the present time when there is urgent need for popular education on venereal diseases the publication of this booklet is most opportune. Major Laird is to be congratulated on having made available to the general public much accurate information which will help to dispel existing ignorance on the venereal diseases and their social implications.

The history, prevalence and manifestations of syphilis and gonorrhoea are dealt with simply, concisely and adequately, while the chapter on the tragedy of venereal disease is by no means overdrawn. Every clinic can multiply instances of domestic unhappiness, the result of ignorance or failure to recognize the possibilities and potential seriousness of syphilis and gonorrhoea: It is perhaps of minor importance that the author does not insist that the venereal diseases are statutorily defined as syphilis, chancroid and gonorrhoea but states, " at least five different conditions are included in the group of venereal diseases:" This number is however in accord with modern medical practice in which many conditions other than the statutory venereal diseases are indiscriminately referred to the V.D: clinics for treatment.

Laird strongly advocates the control of venereal diseases by compulsory measures and points out the successes achieved in Sweden. Those who are interested in the question of compulsory treatment should read the Report on Anti-Venereal Measures in Certain Scandinavian Countries and Holland [Reports.P.H. and Med. Subjects, No. 83] (H.M.S.O.). It is by no means universally accepted that these measures would prove equally successful in Great Britain, and in the opinion of many, comprehensive education and confidential application of contact and default tracing would be just as efficacious. These are undoubtedly essential preliminaries to any scheme of limited or universal notification.

This book can be unreservedly commended and should be widely circulated among and read by the general public to whom it will assure the individual protection resulting from knowledge which may save themselves and others much misery.

A. E. W. McL.

\section{CORRESPONDENCE}

\section{FAILURE OF KAHN TEST}

Sir,-During the last year it has become more and more obvious that the Kahn test as performed in this laboratory is becoming less sensitive. It is now a fairly frequent occurrence to obtain a strongly positive Wassermann reaction and a completely negative Kahn test using a serum from a known syphilitic patient.

I have tested in parallel such serums with seven different brands of Kahn antigen (including three of my own) with similar results. I then was fortunate enough to obtain some Kahn antigen brought by air from the U.S.A. but no improvement was evident. Thus it is doubtful if the antigen is at fault.

Furthermore, I was unable to demonstrate any zone phenomenon by decreasing or increasing the doses of serum, and performing the test at $37^{\circ} \mathrm{C}$. or ice-box temperature appeared to make no difference.

The phenomenon occurs. with serums obtained from patients suffering from any stage of syphilitic infection with or without treatment, but it is not constant with samples of serum taken from the same patient at different times.

I suggest that perhaps the present-day diet may be accountable. I should therefore be glad if Service and civil pathologists would give me their experience of the Kahn test as performed at the present time.-I am, etc.,

The London County Council (Whitechapel) Clinic,

I. N. ORPWOOD PRICE Mile End, E.1.

\section{MEDICAL SOCIETY FOR THE STUDY OF VENEREAL DISEASES}

PROGRAMME FOR. GENERAL MEETINGS, 1944

All meetings are held at 11, Chandos Street, Cavendish Square, London, W.1, on Saturdays at 2.30 p.m. January 29th

Subject : Intensive Arsenotherapy.

February 26th

Speakers : Lt.-col. D. M. Pillsbury, Capt. C. J. Courville and Capt. C. R. Wise.

March 25th

Subject: The Prophylaxis of Venereal Diseases.

Speaker: Col. J. E. Gordon.

$\begin{array}{ll}\text { April 29th } & \text { Speaker: Dr. Nora Wattie. } \\ & \text { Speaker: Dr. W. D. Nicol. }\end{array}$ 